\title{
Erratum to: Effects of Crimping on Mechanical Performance of Nitinol Stent Designed for Femoral Artery: Finite Element Analysis
}

\author{
F. Nematzadeh and S.K. Sadrnezhaad
}

\section{Erratum to: J. of Materi Eng and Perform}

DOI 10.1007/s11665-013-0635-7

Please note that the second of the two affiliations provided for Dr. Nematzadeh at the foot of the title page for this article (that for Materials and Engineering Research Center [MERC]) should not be used for this author.

So Dr. Nematzadeh's sole affiliation is:

Department of Materials Engineering, Faculty of Engineering, Arak University, 38156-88349 Arak, Iran.

The online version of the original article can be found under doi: 10.1007/s11665-013-0635-7.

F. Nematzadeh, Department of Materials Engineering, Faculty of Engineering, Arak University, 38156-88349 Arak, Iran; and S.K. Sadrnezhaad, Department of Materials Science and Engineering, Sharif University of Technology, 11155-9466 Tehran, Iran. Contact e-mail: fardinnematzadeh@gmail.com. 